\title{
DIREITOS HUMANOS E POLÍTICAS MIGRATÓRIAS NA CONTEMPORANEIDADE
}

\author{
$*$ \\ Maiquel Ângelo Dezordi Wermuth \\ Universidade Regional do Noroeste do Estado do Rio Grande do Sul - UNIJUÍ - Brasil \\ Joice Graciele Nielsson \\ Universidade Regional do Noroeste do Estado do Rio Grande do Sul - UNIJUÍ - Brasil
}

\section{Resumo}

$\mathrm{O}$ artigo que segue perspectiva a situação dos migrantes na contemporaneidade. Nesse sentido, advoga a construção de alternativas às políticas migratórias brasileiras, constituídas historicamente a partir dos princípios de um estado de polícia, sob a ótica repressivista e utilitarista. Tais alternativas consistem na proposição de uma virada paradigmática na compreensão do que "são" os migrantes e do desvelamento de sua dimensão humana, permitindo a sua existência mesma, enquanto "potencialidades" na sociedade global. Para tanto, reivindica a possibilidade de profanação, tal como proposta pelo filósofo italiano Giorgio Agamben, enquanto condição de possibilidade de uma nova política, um novo ser humano, uma nova comunidade, que promova a potência $d a$ vida. $\mathrm{O}$ método empregado na investigação é o fenomenológico hermenêutico, marcado pela invasão da filosofia pela linguagem a partir de uma pós-metafísica de reinclusão da faticidade que passa a atravessar o esquema sujeito-objeto, estabelecendo uma circularidade na compreensão. Como resultado da investigação, procura-se demonstrar que, no caso dos migrantes, a profanação reivindicada significa considerá-los "tal qual são", ou seja, não esperar que eles cumpram com esta ou aquela função no contexto de uma determinada sociedade, mas viabilizar que eles sejam potencialidades. Com efeito, o ser "tal qual" dos imigrantes pode ser considerado como uma importante forma de resistência que emerge na sociedade do controle biopolítico.

Palavras-chave: Biopolítica, Migrantes, Política Migratória, Profanação.

\section{CONSIDERAÇÕES INICIAIS}

O tema da imigração no Brasil convida à reflexão. Em primeiro lugar, porque o país vem se consolidando como uma das economias mundiais mais importantes, e começa a atrair a atenção dos imigrantes. Em segundo lugar, porque o Brasil ainda não possui uma regulamentação jurídica adequada do tema, razão pela qual os imigrantes aqui residentes particularmente os que se encontram em situação irregular e sem qualificação suficiente para o mercado de trabalho - tem enfrentado uma política securitarista e autoritária que se aproveita da margem discricionária que o "vácuo legislativo" acerca do tema proporciona. 
Com efeito, a política migratória brasileira é marcada por uma postura utilitarista e repressivista: ao "bom imigrante", o país abre as portas e concede incentivos; à "má imigração" são direcionadas medidas restritivas e policialescas que afrontam diretamente direitos fundamentais consolidados na Constituição Federal. As medidas desenhadas pelo Estatuto do Estrangeiro em vigor (Lei $n^{\circ}$ 6.815/1980) são anacrônicas e demonstram muitos pontos de conflito com o Texto Constitucional, uma vez que o referido Estatuto encontra-se fundamentado em questões de segurança nacional típicas de regimes ditatoriais.

O Projeto de Lei ${ }^{\circ}$ 5.655/2009 - que visava a substituir o Estatuto em vigor continuava atrelado ao mesmo paradigma: propunha procedimentos administrativos burocratizados, além de outros retrocessos em relação ao vetusto Estatuto. Medidas policialescas injustificadas como a que prevê que o imigrante deveria comprovar sua estada regular no território nacional sempre que houver exigência nesse sentido por parte de autoridade policial ou seu agente, permeavam a redação do Projeto. A discriminação também se evidenciava quando o Projeto estabelecia que a política migratória deveria objetivar, primordialmente, a admissão de mão-de-obra especializada adequada aos vários setores da economia nacional.

A inspiração da legislação brasileira tem se vinculado ao paradigma que coloca o imigrante em uma situação constante de suspeição, uma fonte potencial de riscos, criando situações de discriminação que violam o disposto no Texto Constitucional, notadamente seu objetivo fundamental de "promover o bem de todos, sem preconceitos de origem, raça, sexo, cor, idade e quaisquer outras formas de discriminação" (art. $3^{\circ}$, inciso IV).

Tais disposiçõos legais, quando combinadas às práticas arbitrárias dos órgãos encarregados pelas políticas migratórias - particularmente a atuação da Polícia Federal demonstram a existência de uma cesura entre nacionais e imigrantes e, dentre os últimos, entre imigrantes "úteis" e "inúteis" ao desenvolvimento econômico do país, evidenciando o caráter biopolítico da gestão da imigração no Brasil. Estas sucessivas cesuras são típicas de um "racismo de Estado" - consoante revelado na obra foucaultiana - e servem para fragmentar o contínuo biológico ao qual se dirige o biopoder. A partir delas, têm-se a produção da vida nua, do homo sacer, figura do direito romano arcaico resgatada na obra do filósofo italiano Giorgio Agamben, que ilustra perfeitamente o status dos imigrantes na contemporaneidade.

Diante de um contexto tal, o pensar alternativas, novos rumos, e a construção - ou remoção - de marcos regulatórios adequados assume especial relevância. E essas alternativas requerem uma nova compreensão acerca do "ser" dos imigrantes diante da configuração da 
sociedade mundial. É com esse tema que se ocupa o presente artigo, ou seja, com a proposição de uma nova perspectiva de análise da questão da imigração, descomprometida com ideais utilitaristas e repressivistas.

\section{O "MODO-DE-SER" MIGRANTE COMO PROFANAÇÃO DO SAGRADO NA ORDEM GLOBALIZADA}

Há, na contemporaneidade, uma forte tendência em considerar a população migrante enquanto "supérflua", "passiva" e, portanto, destinatária de medidas punitivas e segregacionistas, que visam a afastá-las do convívio daqueles indivíduos que se encontram plenamente integrados na sociedade "globalizada". O combate aos "parasitas sociais" - seja por meio das políticas criminais punitivistas assentadas no paradigma da "tolerância zero", seja por meio das normas recentes tendo por objetivo frear os fluxos migratórios e/ou regulamentá-los em relação a interesses estritamente utilitaristas/mercadológicos - são um claro exemplo disso ${ }^{1}$.

Aliados a este cenário, evidencia-se a cada vez mais frequente contaminação das políticas migratórias por conceitos/práticas gestados no bojo do chamado Direito Penal do Inimigo (JAKOBS, 2004), notadamente após os atentados terroristas ocorridos no início deste milênio e da constante associação entre imigração e terrorismo (BAUMAN, 2005).

O que ocorre, na verdade, assevera Sayad (1998, p. 56), é que todo o discurso sobre o imigrante e a imigração é um discurso imposto. Mais do que isso, "é até mesmo toda a problemática da ciência social da imigração que é uma problemática imposta.” E o fato de se perceber o imigrante, defini-lo, pensá-lo, ou simplesmente falar dele sempre como um "problema" evidencia uma das formas dessa imposição. Efetivamente, nos discursos construídos sobre o tema, é comum associar a figura do migrante a problemas sociais: ao desemprego, à habitação, à educação, à seus filhos e a escola, ao direito de voto, à questão da sua integração, à velhice etc. É necessário, então, retirar o migrante da condição de "sujeito de risco" que lhe é relegada por esses discursos, desativando dispositivos que geram assimetrias e lógicas excludentes e que conduzem à mixofobia (BAUMAN, 2009).

Nesse rumo, uma nova perspectiva para análise do tema pressupõe inicialmente, a superação da concepção equivocada de que os migrantes são os principais vitimados pela

\footnotetext{
${ }^{1}$ Paradigmaticamente, pode-se referir, aqui, a Diretiva no 2008/115/CE, denominada "Diretiva de Retorno" (aprovada pelo Parlamento Europeu em 16 de dezembro de 2008 e publicada no Jornal Oficial da União Europeia em 24 de Dezembro de 2008). O texto integral da Diretiva encontra-se disponível em: <http://www.europarl.europa.eu/sides/getDoc.do?type=TC\&reference=P6-TC1-COD-2005-

0167\&language $=\mathrm{PT}>$. Acesso em 11 ago. 2016.
} 
nova ordem mundial e ocupantes por excelência dos "não-lugares" reservados aos excluídos da multidão global. Na realidade, essas classes estão incluídas na produção social: "apesar da infinidade de mecanismos de hierarquia e subordinação", eles "estão constantemente expressando uma enorme força de vida e produção.” (HARDT; NEGRI, 2005, p. 175).

Tal nova compreensão requer a alteração das perspectivas de análise do social. Antes de enxergar nos migrantes meras vítimas e/ou agentes de situações conflitivas e problemáticas, é preciso reconhecê-los como agentes poderosos. Sua exclusão é apenas parcial e quanto mais observarmos suas vidas e atividades, mais constataremos sua enorme força criativa e sua participação na produção social, o que os tornam partes da multidão. Com efeito, a sua inclusão em várias formas de prestação de serviços, seu papel central na economia de diversos países, sua mobilidade em amplas migrações, bem demonstram o quanto esse processo encontra-se avançado em âmbito mundial (HARDT; NEGRI, 2005).

Esta integração econômica evidencia uma tendência em considerar os migrantes enquanto um mero "exército industrial de reserva", uma massa de trabalhadores industriais em potencial que se encontram em uma condição temporária de desemprego, mas que podem a qualquer momento ser reintegrados à produção ocupando, por exemplo, postos subalternizados que não são preenchidos pelos cidadãos "qualificados". Esse exército de reserva, passa a ser concebido como uma ameaça constante que pende sobre a classe operária, porque sua pobreza serve de exemplo assustador para os trabalhadores do que pode eventualmente lhes acontecer, e porque a oferta excedente de mão-de-obra que essa população representa significa uma redução do custo de mão-de-obra que solapa o poder dos trabalhadores em face dos empregadores (por exemplo, servindo como potenciais "furagreves").

O ressurgimento dessas velhas teorias sobre o papel negativo desempenhado pelo "exército industrial de reserva" ocorre no contexto da globalização, quando as grandes corporações tiram vantagem sobre enormes diferenças salariais e de condições de trabalho em diferentes países, por meio de uma espécie de "dumping trabalhista" que adota a estratégia de deslocamento de empregos pelo mundo afora para baixar seus custos.

Essa lógica viabiliza um aumento da exploração dos trabalhadores imigrantes, criando, segundo Santos (2012, p. 365), "uma camada de explorados-nômades a serviço de patrõessedentários"2. Nesta racionalidade, os migrantes são "usados, abusados e logo descartados

\footnotetext{
2 Santos (2012, p. 356) utiliza os tipos do "pastor" e do "camponês" para investigar axiologicamente os processos de institucionalização da persecução penal dos movimentos migratórios, salientando que "tais tipos não equivalem necessariamente e in concreto a quaisquer eventos reais, porém materializam dois modos-de-ser-
} 
quando não forem mais necessários para o desenvolvimento das economias nacionais, para depois serem devolvidos aos seus países de origem." Trata-se, em última análise, de uma tipologia dicotômica, segundo a qual “o forasteiro-nômade é 'mau' porque vem para ocupar o lugar econômico do nacional 'bom"”.

Uma alteração de perspectiva na análise da temática requer, então, que os migrantes, para além de integrantes de um exército de reserva que oneram um Estado esfacelado, sejam compreendidos como ativos na produção social, uma vez que as suas próprias estratégias de sobrevivência diante da escassez e da ausência da tutela estatal exigem uma extraordinária habilidade e criatividade.

Neste sentido, a própria luta dos pobres contra essa condição - em grande parte representada pelos movimentos migratórios - não é apenas uma poderosa arma de protesto, mas uma afirmação do seu poder biopolítico, revelando, assim, um "ser" que é mais poderoso que o "ter". Se ao longo do século XX os movimentos dos pobres nos países dominantes superaram a fragmentação, o desânimo, a resignação e até mesmo o pânico ocasionado pela pobreza, ao exigir dos governos nacionais a redistribuição da riqueza, hoje esses movimentos são potenciados, assumindo um caráter mais geral e biopolítico, pois colocados em nível global. Suas linguagens se misturam e interagem formando não uma linguagem unificada, mas uma força comum de comunicação e cooperação (HARDT; NEGRI, 2005).

Essa produção de subjetividade e do comum formam, juntas, uma relação simbiótica em forma de espiral. Quer dizer, “a subjetividade é produzida através da cooperação e da comunicação, e por sua vez esta subjetividade produzida vem a produzir novas formas de cooperação e comunicação, que por sua vez produzem nova subjetividade, e assim por diante.” E, nessa espiral, "cada movimento sucessivo da produção de subjetividade para a produção do comum é uma inovação que resulta numa realidade mais rica." Essa realidade mais rica, por sua vez, pode ser compreendida como a formação do corpo da multidão, "um tipo fundamentalmente novo de corpo, um corpo comum, um corpo democrático." (HARDT; NEGRI, 2005, p. 247-248).

Quer dizer: ao contrário do que se afirma majoritariamente, o exemplo dado pelos "excluídos" da sociedade globalizada pode ser compreendido justamente como um importante contributo para a revitalização do tecido societal. A virada paradigmática proposta, então,

no-mundo que expressam, tipologicamente, a situação problemática historicamente vivida pelos imigrantes e refugiados e os seus perseguidores." Isso porque "o pastor e o camponês, figurados pela narrativa genealógica e mitológica, são dois modos-de-ser-no-mundo; dois mundos que se afirmam e se opõem, tornando-se, com o passar do tempo, pretextos teóricos para questões metafísicas, ideológicas e depois políticas. Cosmopolitismo dos viajantes nômades contra nacionalismo dos camponeses sedentários, oposição que agita a história desde o neolítico até as formas mais contemporâneas do imperialismo." 
perpassa pela mudança de compreensão do que "são" os migrantes: antes de qualquer consideração utilitarista, é imprescindível que se desvele a sua dimensão humana. Em última análise, é preciso libertá-los do cumprimento de qualquer tarefa, permitindo a sua existência mesma, enquanto "potencialidades".

Esta tarefa deve ser empreendida em um contexto no qual o debate sobre o tema, assentado na lógica do nacionalismo e da soberania cria espaços de "tolerância" para aqueles que se amoldam ao "padrão" considerado universal, assentado na ideia de permanência, tradição, aprisionamento e exclusão, amparados por discursos "recheados de preconceito, de injustiça, de discriminação e de violência em relação ao 'Outro', que facilmente transformamse em repressões pelos aparelhos de Estado, até mesmo pela via penal.” (SANTOS, 2012, p. 361).

Por outro lado, o modo-de-ser dos migrantes parte de uma lógica absolutamente diversa: existir enquanto "pastor-nômade-cosmopolita" significa compreender a "diferença, no Outro, num vir-a-ser de encontros com o pluralismo e com a diversidade." Aqui, os discursos assentam-se na ideia de encontro, de renovação, de liberdade, inclusão, de "hibridização de tradições que levam a novas e inusitadas combinações dos seres humanos, culturas, ideias, políticas, filmes, canções.” Nesse rumo, os migrantes representam "movimentos em busca de vida", e os valores que os movem "são fundamentalmente vitais, pois têm como referência os seres humanos, valoram os seres humanos." (SANTOS, 2012, p. 361-362).

Essas matrizes fluidas, articuladas por meio de redes, podem configurar um perfeito exemplo de globalização ascendente ou contra-hegemônica. Isso porque não existe "a" globalização: o que ocorre apenas é que "frequentemente o discurso da globalização é a história dos vencedores contadas por estes", o que faz com que os "derrotados" sejam olvidados (SOUSA SANTOS, 2008, p. 195). Portanto, na esteira de Sousa Santos (2008 p. 195-196), é preciso reconhecer a existência de "globalizações", ou seja, de "feixes de relações sociais" que envolvem, necessariamente, conflitos e que, na medida em que se transformam, também transformam a globalização. Assim, para além da globalização (hegemônica) econômica, é possível falar em "outras globalizações", contra-hegemônicas, que, em todo o mundo, oferecem "diferentes formas de resistência - iniciativas populares de organizações locais, articuladas com redes de solidariedade transnacional - que reagem contra a exclusão social” de forma a abrir espaço para "a participação democrática, para a construção da comunidade, para alternativas a formas dominantes de desenvolvimento e de conhecimento, 
em suma, para novas formas de inclusão social", constituindo, assim, "um novo movimento democrático transnacional."

Nesse sentido, como destaca Ferreira (2011, p. 264), os imigrantes, pela sua própria existência - e não necessariamente por meio de manifestações políticas conscientes - acabam por subverter o lugar comum (topoi) e obrigam a coletividade "a questionar a validade de conceitos e identidades estanques, fixas, imutáveis (conceitos e identidades emuralhadas).” Isso porque os migrantes "promovem o pensamento e a prática do kosmopolites, fazendo com que a Soberania territorial, dogmática e exclusiva, seja contestada.”

Nesse ponto, como condição de possibilidade para que essa nova leitura do tema da imigração seja empreendida, é imprescindível compreender que, no fundo, democracia e totalitarismo fundam sua soberania em um mesmo movimento, qual seja, o que faz da vida sua condição de possibilidade, o movimento que por meio da exclusão busca alcançar o que se lhe afigura como mais estranho: a zoé, a vida nua - conforme descortinado pela obra foucaultiana (2012) e agambeniana (2010).

Como ressalta Pérez (2010, p. 48), “en el fondo, todo regímen político, sea democrático o no, sigue fundamentando su soberania en la posibilidad de decidir quién pertenece y quién no pertenece a la comunidad, quién es el amigo y quién el enemigo, qué merece vivir y qué merece morir". Todo Estado, por mais democrático que se conceba, “necessita desplegarse como máquina gubernamental para poder produzir zonas de excepción, de vida nuda, para poder distinguir a cada instante bíos y zoé." Isso é imprescindível para que se possa contar com uma "reserva" de vida nua disposta a converter-se em qualquer forma de vida social e politicamente funcional. Buscar a superação dessa lógica é medida que se impõe. E é a partir dessa superação que uma nova perspectiva de compreensão da imigração - nos moldes até então delineados - será viabilizada.

\section{A COMUNIDADE QUE VEM E A PROFANAÇÃO COMO CONDIÇÃO DE POSSIBILIDADE PARA A RECUPERAÇÃO DO "SER-TAL" DOS MIGRANTES}

Diante do panorama até aqui analisado, condição de possibilidade deste novo paradigma pressupõe uma vida em comunidade que supere a lógica soberana. Nas palavras de Pérez (2010, P. 48), requer "una entidad sin soberanía - entendiendo que el movimento soberano original implica la distinción entre zoé y bíos -, una comunidad que tendría la possibilidad de superar la escisión entre zoé y bíos debido a su carácter positivo, no excluyente." 
Verifica-se, aqui, claramente, o movimento apreendido pela obra agambeniana (2010): por meio das declarações de direitos (que representam a passagem da soberania régia e de origem divina à soberania nacional), o "súdito" se transforma em "cidadão", e o seu nascimento marca a inscrição da sua vida nua na lógica da soberania. As declarações de Direitos, nesse sentido, seriam justamente o locus da inscrição moderna da biopolítica. Ao lado de sua função emancipatória, cumprem também com a função de "abandono" da vida nua à violência dos mecanismos de poder.

Nesse sentido é que a obra de Agamben (2013) se afigura de extrema importância. Ao analisar a noção de comunidade, o autor busca subtrair dela qualquer fator negativo: tudo passa a ser inclusão, pertencimento, propriedade, possibilidade. A comunidade, aqui, é expropriada de todas as identidades para que possa se apropriar do pertencimento mesmo (existencial).

Na verdade, na proposta de Agamben, a dicotomia inclusão/exclusão perde qualquer sentido, tornando-se obsoleta, e dando lugar a uma nova política, assentada na lógica da amizade e em outra experiência do tempo, capaz de expor o homem efetivamente às exigências de compartilhamento da existência. $\mathrm{O}$ indivíduo, nesse marco, não precisa cumprir com nenhum requisito, elaborar nenhuma justificativa, senão somente "ser tal qual é". Daí a afirmação de Agamben (2013, p. 9) de que “o ser que vem é o ser qualquer”, e a única divisão admissível em uma comunidade é a divisão puramente existencial. Não se admite, aqui, divisões e partilhas de classes de fundação comunitária ou a ausência genérica de condições de fundação. Nesse contexto,

o ser-qual é recuperado do seu ter esta ou aquela propriedade, que identifica o seu
pertencimento a este ou aquele conjunto, a esta ou aquela classe (os vermelhos, os
franceses, os muçulmanos) - e recuperado não para uma outra classe ou para a
simples ausência genérica de todo pertencimento, mas para o seu ser-tal, para o
próprio pertencimento. Assim, o ser-tal, que permanece constantemente escondido
na condição de pertencimento ('há um $x$ tal que pertence a y') e que não é de modo
algum um predicado real, vem, ele mesmo, à luz: a singularidade exposta como tal é
qual-se-queira, isto é, amável. (AGAMBEN, 2013, p. 10-11).

Assim como o ser, deve-se propugnar por uma comunidade que vem: esta não é a comunidade que virá, mas a comunidade que nunca chega, que está em constante devir. Uma comunidade que vem - e que, por consequência, jamais termina de chegar - se afigura, nesse contexto, enquanto condição de possibilidade para que se possa evitar a expressão soberana por excelência e as cesuras que lhe subjazem: distinções entre o que está dentro e o que está fora, entre o que é próprio e o que é estranho, entre nacionais e estrangeiros, enfim, entre zoé e bíos. Como destaca Pérez (2010, p. 48), “una comunidad que jamás termina de llegar nunca 
está lo suficientemente acabada para dar lugar a tal movimiento soberano.” Em razão disso, a comunidade que vem só pode ser uma comunidade na qual a política é a amizade, ou seja, a “com-divisão" da própria existência.

O ser que vem, e que habita a comunidade que vem, então, é aquele que permanece, ao mesmo tempo, aberto e singular. Ele se funde no geral preservando sua singularidade. Em síntese, é o ser inacabado, aberto a outras possibilidades. Este ser amável definido por Agamben (2013) é o ser com todos os seus predicados, o ser tal qual é.

Com efeito, o amor não se dirige apenas a algumas peculiaridades do ser amado (características físicas ou psicológicas específicas, por exemplo), e tampouco prescinde destas particularidades em nome de uma insípida generalidade (amor universal): ele quer o ser com todos os seus predicados, o seu ser tal qual é. Deste modo, "a singularidade qualquer (o Amável) não é jamais inteligência de alguma coisa, desta ou daquela qualidade ou essência, mas somente inteligência de uma inteligibilidade.” (AGAMBEN, 2013, p. 11). Em outras palavras, reconhecer alguém como amigo, como um ser amável, é justamente não poder reconhecê-lo como “algo", uma vez que "não se pode dizer 'amigo' como se diz 'branco', 'italiano' ou 'quente' - a amizade não é uma propriedade ou uma qualidade de um sujeito." (AGAMBEN, 2009, p. 85).

Ser tal-qual $^{3}$, sem deixar de estar exposto a ser de outra maneira é o que revela, segundo Agamben (2013), o milagre do mundo. Esse "ser tal qual" - do mundo e de todo o ser - é o "irreparável" 4 , aquilo que é assim e não de outra maneira, mas que está exposto a ser de qualquer outra forma. Somente a partir do momento em que o "irreparável do mundo" é percebido, ou seja, em que as coisas em sua exposição sejam como são, é que se torna possível a salvação, uma salvação imanente que implica, antes de tudo, uma comunidade sem soberania: trata-se da salvação do caráter profano do mundo.

Nesse rumo, "ser tal qual" é ser exposto, o que significa uma vida sempre aberta a tomar esta ou aquela forma, sem jamais consolidar-se de maneira permanente em uma forma de vida dada, senão ser "forma-de-vida". Dito de outra forma: em oposição às diversas formas de vida codificadas socialmente, a forma-de-vida é aquela que não demanda a separação entre

\footnotetext{
3 “Tal qual. Aqui a anáfora tal não remete a um termo referencial precedente (a uma substância pré-linguística) e qual não serve para identificar um referente que dê ao tal o seu sentido. o qual não tem outra existência a não ser o tal, e o tal não tem outra essência a não ser o qual. Eles se contraem um sobre o outro, se expõem mutuamente, e o que existe é o ser-tal, uma tal qualidade absoluta, que não remete a nenhum pressuposto." (AGAMBEN, 2013, p. 90).

${ }^{4}$ Como esclarece Agamben (2013, p. 43-44), “irreparável significa que elas [as coisas] são consignadas sem remédio ao seu ser-assim, que elas são, antes, precisamente e somente o seu assim [...]; mas significa, também, que, para elas, não há literalmente nenhum abrigo possível; que, no seu ser-assim, elas estão agora absolutamente expostas, absolutamente abandonadas."
} 
zoé e bíos, mas conserva a potência para ser de qualquer forma. Trata-se, aqui, segundo Pérez (2010, p. 49), de "una vida que conserva su apertura, su exposición; de ahí que Agamben apunte que en tal forma-de-vida es imposible separar o aislar algo como la vida nuda." Deste modo, "en una comunidad sin soberanía la separación de zoé y bíos resulta improcedente, porque la bíos conserva la apertura y exposición de la zoé."

Em síntese: é preciso pensar para além do sujeito, pensar uma "singularidade qualquer (quodlibet)" (AGAMBEN, 2013). A resolução do nexo entre lei e vida só é possível a partir dessa forma-de-vida que veda qualquer distinção entre zoé e bíos. Unidas, zoé e bíos se apresentam como condição de possibilidade para a superação de qualquer forma de exceção e, reflexamente, produção de vida nua.

Enquanto devir perene, a comunidade se opõe a qualquer forma de acabamento, o que suscita a questão sobre como escapar à concreção do processo e permanecer como abertura às possibilidades. Assume relevância, então, a ideia de inoperosidade cunhada por Agamben (2013) e que serve como resposta à objeção. Aqui, a saída não reside em uma potência que nunca passa ao ato. Ao contrário, ela pressupõe uma potência que, ao passar ao ato sobrevive nele: suas possibilidades não se esgotam no ato, mas permanecem apesar do ato. Segundo Pérez (2010, p. 50), a potência "permanece como capacidad de desplegar el poder de no ser, resistirse a la concreción y al agotamiento en formas de vida últimas y acabadas."

É importante destacar que o poder de não ser não se afigura enquanto mera passividade. Ele é considerado um poder verdadeiro, uma potência negativa que se esforça em não se esgotar, em não se concretizar nem em sua total negação nem em sua total afirmação. Eis o "ser tal" dos migrantes.

Assim como é capaz de ser, este poder é capaz de não ser. Como salienta Agamben (2013, p. 40), "somente uma potência que pode tanto a potência quanto a impotência é, então, a potência suprema. Se toda potência é tanto potência de ser quanto potência de não ser, a passagem ao ato só pode advir transportando [...], no ato, a própria potência de não ser.”

Desse modo, a noção de inoperosidade cunhada por Agamben não está relacionada à ideia de levar algo à inércia, à ineficácia. Pelo contrário, o autor preocupa-se em pensar uma categoria que viabilize um novo uso do que é posto em inoperosidade, razão pela qual "o movimento que torna inoperoso deve portanto deixar a potência intacta, cancelando somente as finalidades e as modalidades nas quais o seu exercício era investido." (NASCIMENTO, 2012, p. 220). Dessa forma, as funções de uso do que é conduzido à inoperosidade sofrem uma considerável variação, mas não se anula inteiramente a possibilidade de usar. 
Em Agamben (2013), “inoperosidade não significa inércia, mas katargesis - isto é, uma operação na qual o como substitui integralmente o que, na qual a vida sem forma e as formas sem vida coincidem em uma forma de vida." Assim, pode-se acrescentar que "a inoperosidade sugere um modo diverso de ser, um modo diverso de agir e de viver, ainda que isso determine apenas a transformação do mesmo." (NASCIMENTO, 2012, p. 220).

O conceito de inoperosidade, portanto, se mostra fundamental para que se possa pensar em uma forma de se desarticular a relação entre direito e violência, de modo a desativar os dispositivos que viabilizam o aprisionamento do homem às redes biopolíticas da contemporaneidade. Daí a afirmação de Agamben no sentido de que nada é mais urgente do que a inclusão da inoperosidade nos próprios dispositivos (AGAMBEN, 2009).

Nesse rumo, pode-se afirmar que a superação da soberania implicaria chegar a uma comunidade na qual é impossível a cisão entre zoé e bíos e, por consequência, não existe a figura da exceção. Em um modelo tal, tudo é pertencimento e se torna desnecessário o isolamento e a divisão. Não há espaço, portanto, para a mixofobia, e é possível, então, "ser tal qual é”, ou seja, ser pura exposição, possibilidade que se nega a assumir uma forma de vida determinada.

Em um mundo tal, Ferreira (2011, p. 263) reconhece que o imigrante não mais seria um problema. Ele apenas seria uma pessoa que se locomove por onde quer, escolhendo o lugar da sua residência, da sua morada. Nesse sentido, a figura do imigrante é interessante para a compreensão da proposta agambeniana: "ao mesmo tempo em que é visto como problema por muitos governos atuais, ele pode ser visto como uma potencialidade subversiva de derrubar as muralhas, derrubar as fronteiras." Os migrantes trazem, assim, em sua própria característica de “'andar pelo mundo', 'viajar pelo mundo', uma centelha revolucionária (semelhante aos ciganos...)."

Agamben (2013) assevera que a vida nua foi, paradoxalmente, excluída da política e, concomitantemente, incluída e capturada através da sua exclusão, o que significa que a vida nua pode ser compreendida enquanto o fundamento negativo do poder. Na biopolítica moderna, essa separação atinge sua forma extrema: o cuidado e a decisão sobre a vida nua se tornam aquilo que está em jogo na política. Isso fica evidente a partir do que aconteceu nos estados totalitários do século XX: em todas essas experiências, o poder (que também assume a forma da ciência, como no exemplo do nazismo) é quem decide, em última análise, sobre o que é uma vida humana e sobre o que ela não é. É por isso que o autor propõe o "pensar numa política das formas de vida, a saber, de uma vida que nunca seja separável da sua forma, que jamais seja vida nua." 
Aqui, a tarefa da profanação se apresenta como primordial e assume o sentido de fazer com que as coisas que saíram da esfera do humano por meio da "consagração" sejam restituídas ao livre uso dos homens. Se a consagração designa a separação entre a esfera dos deuses e dos homens ${ }^{5}$, etimologicamente, "puro, profano, livre dos nomes sagrados, é o que é restituído ao uso comum dos homens.” (AGAMBEN, 2007, p. 65). Assim, “profanar designa o ato de restituir ao livre uso e comércio dos homens o que antes fora separado por algum tipo de consagração, interdição, indisponibilidade.” (NASCIMENTO, 2012, p. 224).

É importante, então, destacar a diferença estabelecida entre secularização e profanação: a primeira "é uma forma de remoção que mantém intactas as forças, que se restringe a deslocar de um lugar a outro", de forma que "a secularização política de conceitos teológicos (a transcendência de Deus como paradigma do poder soberano) limita-se a transmutar a monarquia celeste em monarquia terrena, deixando, porém, intacto o seu poder." Já a profanação refere-se à "neutralização daquilo que profana. Depois de ter sido profanado, o que estava indisponível e separado perde a sua aura e acaba restituído ao uso." Assim, enquanto a secularização assegura o poder remetendo-o a um modelo sagrado, a profanação "desativa os dispositivos do poder e devolve ao uso comum os espaços que ele havia confiscado." (AGAMBEN, 2007, p. 68).

$\mathrm{O}$ ato de profanar pode ser compreendido como uma forma especial de negligência, que ignora a separação operada pela religião, ou melhor, faz dela um uso particular. Profanar não significa apenas a abolição das separações, mas, sobretudo, aprender a fazer delas um novo uso, brincar com elas. Desse modo, a profanação pode assumir a forma de um jogo, que nada mais é que um uso totalmente incongruente do sagrado, uma vez que "a maioria dos jogos que conhecemos deriva de antigas cerimônias sacras, de rituais e de práticas divinatórias que outrora pertenciam à esfera religiosa em sentido amplo." Dessa forma, “o jogo libera e desvia a humanidade da esfera do sagrado, mas sem a abolir simplesmente. $\mathrm{O}$ uso a que o sagrado é devolvido é um uso especial, que não coincide com o consumo utilitarista." Nessa ótica, “da mesma forma que a religio não mais observada, mas jogada, abre a porta para o uso, assim também as potências da economia, do direito e da política, desativadas em jogo, tornam-se a porta de uma nova felicidade.” (AGAMBEN, 2007, p. 6667).

Aqui, novamente, o "ser tal" dos migrantes permite uma aproximação à ideia de profanação: não sendo nem "daqui” nem "de lá”, o migrante se torna forte, justamente por

\footnotetext{
5 Analisando a etimologia do termo religião, Agamben $(2007$, p. 66) constata que religio "não é o que une homens e deuses, mas aquilo que cuida para que se mantenham distintos."
} 
dissolver a noção do "cá" e do "lá" enquanto expressões da soberania e, consequentemente, rígidos e excludentes. A partir desse processo, o "cá" e o "lá" se fundem, dando lugar a "outra coisa" (FERREIRA, 2011).

Segundo Agamben (2013), a tarefa que nos espera consiste, portanto, em pensar integralmente aquilo que até agora havíamos definido com a expressão, de resto pouco clara em si mesma, 'vida política'. O autor nos convida a reexaminar as bases da autoridade jurídico-política para, ao invés de justificar o poder soberano, conceber uma comunidade política que não o pressupõe. Agamben projeta uma comunidade que está além da tradição da soberania. O abandono das narrativas patrióticas e uma inextrincável relação entre política e subjetividade se impõem.

Para tanto, o autor refere que é preciso ter em mente que "a profanação não restaura simplesmente algo parecido com um uso natural, que preexista à sua separação na esfera religiosa, econômica ou jurídica." Esta operação "é mais astuta e complexa e não se limita a abolir a forma da separação para voltar a encontrar, além ou aquém dela, um uso não contaminado." (AGAMBEN, 2007, p. 74).

Deste modo, é possível afirmar que a atividade que resulta da profanação se transforma em um puro meio, o que significa que ela se transforma em "uma prática que, embora conserve tenazmente a sua natureza de meio, se emancipou da sua relação com uma finalidade, esqueceu alegremente o seu objetivo, podendo agora exibir-se como tal, como meio sem fim.” Em síntese: “a criação de um novo uso só é possível ao homem se ele desativar o velho uso, tornando-o inoperante." E mais: "as formas desse uso só poderão ser inventadas de maneira coletiva." (AGAMBEN, 2007, p. 74-75).

Nesse rumo, tornar inoperante a noção de soberania que promove a separação entre zoé e bíos só é possível por meio da profanação. A biopolítica contemporânea se consolida enquanto um domínio sobre a vida. A profanação, então, é uma forma que se coloca à disposição da humanidade para que se possa resistir a este domínio. Por meio da profanação é possível tentar uma nova política, um novo ser humano, uma nova comunidade, ao promover justamente o avesso à vida nua, qual seja: a potência $d a$ vida. Em outras palavras: a potência da vida humana como potência de ser, mas também como potência de não ser.

No caso dos migrantes, isso significa considerá-los "tal qual são", ou seja, não esperar que eles cumpram com esta ou aquela função no contexto de uma determinada sociedade, mas viabilizar que eles sejam potencialidades. Com efeito, o ser "tal qual" dos imigrantes pode ser considerado como uma importante forma de resistência que emerge na sociedade do controle biopolítico. Como já salientava Foucault (2012, p. 106), as formas de resistência que surgem 
nesse modelo de sociedade não são enraizados em uma espécie de "Grande Recusa". Pelo contrário, o que existe são

resistências, no plural, que são casos únicos: possíveis, necessárias, improváveis, espontâneas, selvagens, solitárias, planejadas, arrastadas, violentas, irreconciliáveis, prontas ao compromisso, interessadas ou fadadas ao sacrifício; por definição, não podem existir a não ser no campo estratégico das relações de poder. (FOUCAULT, 2012, p. 106).

$\mathrm{Na}$ ótica foucaultiana, essas resistências estão distribuídas no tecido social de modo irregular, disseminando-se com mais ou menos densidade no tempo e no espaço, provocando, não raras vezes, o levante de grupos ou indivíduos de forma definitiva. No entanto, essas grandes rupturas são exceções: é mais comum que esses pontos de resistência sejam móveis, transitórios, e que introduzam na sociedade clivagens que se deslocam, rompendo unidades e suscitando reagrupamentos, percorrendo os próprios indivíduos, recortando-os e remodelando-os, enfim, traçando nos seus corpos e almas regiões irredutíveis.

Segundo De Giorgi (2006, p. 109-110), essas resistências se desenvolvem em uma "molecularidade de conflitos difusos", caracterizadas "pela multiplicidade de formas, pela irredutibilidade a qualquer práxis hegemônica, pela hibridação contínua das práticas e pela amplitude com que se manifestam." Elas estão localizadas justamente no interior de uma determinada economia e racionalidade "para sabotá-las, subtraí-las, torná-las ineficazes", ou seja, "minar a sua eficácia por dentro, quase um axioma daquilo que podemos definir como uma genealogia do nexo poder-resistência."

Essas formas de resistência configuram-se como práticas de contestação dos dispositivos que obrigam os indivíduos a acatar identidades pré-constituídas e a se colocar em espaços de controle pré-dispostos. Tratam-se de resistências singulares, subterrâneas, que sempre se tenta ocultar ou invisibilizar, mas que delineiam uma nova cartografia das resistências biopolítica (DE GIORGI, 2006).

A melhor política migratória, aqui, se afigura justamente como aquela que não se ocupa em definir papéis - por exemplo, relacionando ou condicionando a imigração às exigência do mercado e trabalho e/ou ocupando-se precipuamente do controle de fronteiras em defesa dos direitos da "cidadania" em oposição aos direitos dos áliens, utilizando-se, para tanto, de medidas de cunho repressivo na esfera penal. É esta a luta pela ética que se impõe na contemporaneidade: não se está mais diante da necessidade de cumprimento da norma existente, ou da realização desta ou daquela essência humana, ou vocação histórica. A luta pela ética é a luta pela liberdade, ou seja, a luta para que todos possam experimentar sua própria existência como possibilidade ou potência, ou seja, potência de ser e de não ser. 
Os imigrantes são um exemplo paradigmático disso. Como destaca De Giorgi (2006, p. 113-114), o desejo de mobilidade, de subtração e de fuga dos migrantes

\begin{abstract}
esbarra diariamente nos dispositivos de controle e de localização forçada da multidão, expressando uma 'crítica prática' a eles. As políticas de controle das migrações se traduzem numa expropriação sistemática dos desejos, das motivações e das expectativas que inspiram os projetos migratórios. Na metrópole pós-fordista, é retirada a palavara ao migrante, a linguagem e a possibilidade de comunicar a própria condição existencial lhe são tolhidas, reduzindo-o, assim, à afasia. Vemos desenvolver-se aqui, de modo exemplar, a racionalidade dos dispositivos de controle pós-fordistas. Ao mesmo tempo classe trabalhadora e classe perigosa, excesso positivo e excesso negativo, os migrantes devem ser privados exatamente daquelas faculdades comunicativas, linguísticas e afetivas que fazem deles uma subjetividade constitutiva da força de trabalho social. o objetivo é contrastar o autoreconhecimento de si como parte da multidão, de impedir a construção de laços e formas de cooperação social e política que possam dar corpo à rebelião. Os migrantes constituem então uma imagem paradigmática da multidão pós-fordista e indicam, sobretudo, as formas de resistência a que ela pode dar vida, dentro e contra o novo regime do governo do excesso.
\end{abstract}

Uma política migratória adequada a essa perspectiva, portanto, pressupõe abandonar as soluções que nos foram apresentadas pela modernidade. É preciso abandonar a visão de que tudo pode ser resolvido por meio do cumprimento da norma. Em síntese: a profanação pressupõe um abandono na aposta no "Estado de Direito". Isso porque "o fato novo da política que vem é que ela não será mais a luta pela conquista ou pelo controle do Estado, mas a luta entre o Estado e o não-Estado (a humanidade), disjunção irremediável entre as singularidades quaisquer e a organização estatal.” (AGAMBEN, 2013, p. 78).

\title{
4 CONSIDERAÇÕES FINAIS
}

Como salientado no introito deste artigo, as políticas migratórias brasileiras se constituíram historicamente a partir dos princípios de um estado de polícia, preocupado, em demasia, com o tema da segurança nacional, fator dissonante ao estabelecido na Constituição Federal de 1988, que normatiza um extenso leque de direitos e garantias fundamentais, extensivos aos estrangeiros. A complexidade do Estatuto do Estrangeiro vigente no país traz em sua consolidação a constituição do imigrante como um potencial inimigo da ordem nacional, tornando-o, já em primeiro plano, um sujeito de risco.

Em contrapartida, a problemática alimenta sentimentos de ódio por parte dos cidadãos autóctones contra o imigrante, tendo em vista que a própria normatização alimenta um sentimento de desconfiança com o estrangeiro.

A partir das análises referidas, evidencia-se uma incompatibilidade normativa entre a Constituição Federal e o Estatuto do Estrangeiro, estando as políticas migratórias em 
dissonância aos direitos humanos, uma vez que, ao não serem aplicadas com equidade aos imigrantes que ingressam no país, permitem que muitos permaneçam na ilegalidade, o que, consequentemente, dificulta a sua inserção social.

No entanto, não se pode deixar de referir os esforços despendidos para que haja uma reversão desse quadro legislativo - e que oferece substrato para práticas autoritárias - no que se refere ao tema da imigração no Brasil. Cumpre salientar, nesse sentido, a importância da $1^{\text {a }}$ Conferência Nacional sobre Migrações e Refúgio - Comigrar, iniciativa governamental que inovou ao abordar a questão migratória no Brasil, por meio da mobilização nacional e internacional dos diversos atores interessados no tema, fomentando, assim, a discussão dos conceitos centrais da política migratória brasileira. A $1^{\text {a }}$ Comigrar foi realizada entre os dias 30 de maio e $1^{\circ}$ de junho de 2014, na cidade de São Paulo, sob coordenação do Ministério da Justiça, por meio da Secretaria Nacional de Justiça/Departamento de Estrangeiros-DEEST, em parceria com o Ministério do Trabalho e Emprego e o Ministério das Relações Exteriores, com o apoio da Organização Internacional para as Migrações-OIM e do Programa das Nações Unidas para o Desenvolvimento-PNUD. Objetivou-se, com a Conferência, reunir migrantes, profissionais envolvidos na temática migratória, estudiosos, servidores públicos, representações diversas que vivenciam a realidade da migração e do refúgio, para uma reflexão coletiva e elaboração de aportes para a construção da Política e do Plano Nacionais de Migrações e Refúgio.

Na esteira dessas discussões, o Projeto de Lei $n^{\circ} 2.516 / 2015^{6}$ - com origem no Projeto de lei do Senado no 288/2013 - visa a substituir o atual Estatuto do Estrangeiro. Nesse sentido, abandona a perspectiva da segurança nacional do Estatuto, criando garantias para o tratamento igualitário dos migrantes que entram no Brasil. O artigo $3^{\circ}$ do Projeto afirma como princípios da política migratória brasileira, dentre outros, a universalidade, a indivisibilidade e a interdependência dos direitos humanos, enfatizando a acolhida humanitária e repudiando a xenofobia, bem como vedando a criminalização da imigração. Nessa esteira, o projeto também visa à simplificação da regularização da situação do imigrante no país, representando uma alternativa às perspectivas xenofóbicas e discriminatórias que pautam o tratamento legal da imigração na contemporaneidade.

Buscar pelas singularidades quaisquer, que se apropriam do próprio pertencimento e que recusam toda identidade e condição de pertencimento é o primeiro passo do processo que

\footnotetext{
${ }^{6}$ Inteiro teor disponível em: < http://www.camara.gov.br/proposicoesWeb/prop_mostrarintegra;jsessionid=760DEF244F4E907F0565405DF66 E7AED.proposicoesWeb2?codteor=1366741\&filename=PL+2516/2015> . Acesso em: 21 mar. 2016.
} 
tem por objetivo justamente profanar o improfanável, que se afigura como a principal tarefa política da geração que vem.

\title{
HUMAN RIGHTS AND MIGRATORY POLICIES IN CONTEMPORARY
}

\begin{abstract}
The article that follows perspective the situation of migrants in contemporary times. In this sense, advocates the construction of alternatives to Brazilian migration policies, historically constituted on the principles of a police state, from the perspective repressivista and utilitarian. Such alternatives consist in proposing a paradigm shift in the understanding of what "is" migrants and the unveiling of its human dimension, allowing its existence as "potential" in the global society. Therefore, claims the possibility of profanation, as proposed by Italian philosopher Giorgio Agamben, as a condition of possibility of a new policy, a new human being, a new community that promotes the power of life. The method used in research is the hermeneutic phenomenological, marked by the invasion of philosophy by language from a reinclusion postmetaphysical of facticity passing through the subject-object scheme, establishing a circularity in understanding. As a result of research, seeks to demonstrate that, in the case of migrants, claimed desecration means consider them "as it is", ie do not expect them to comply with this or that function in the context of a given society, but enable them to be potential. Indeed, being "as is" of immigrants it can be considered as an important form of resistance that emerges in control of society biopolitical.
\end{abstract}

Keywords: Biopolitics, Migrants, Migration Policy, Desecration.

\section{REFERÊNCIAS}

AGAMBEN, Giorgio. Estado de exceção. Trad. Iraci D. Poleti. São Paulo: Boitempo Editorial, 2004.

Profanações. Trad. Selvino J. Assmann. São Paulo: Boitempo, 2007.

O que é o contemporâneo? e outros ensaios. Trad. Vinícius Nicastro Honesko.

Chapecó, SC: Argos, 2009.

Homo sacer: o poder soberano e a vida nua I. Trad. Henrique Burigo. Belo

Horizonte: Editora UFMG, 2010.

O reino e a glória. Trad. Selvino J. Assmann. São Paulo: Boitempo, 2011.

A comunidade que vem. Trad. Cláudio Oliveira. Belo Horizonte: Autêntica Editora, 2013.

BAUMAN, Zygmunt. Vidas desperdiçadas. Rio de Janeiro: Jorge Zahar, 2005.

Confiança e medo na cidade. Rio de Janeiro: Jorge Zahar, 2009. 
DE GIORGI, Alessandro. A miséria governada através do sistema penal. Trad. Sérgio Lamarão. Rio de Janeiro: Revan, 2006.

FERRAJOLI, Luigi. Derechos e garantias: la ley del más débil. 7. ed. Madrid: Editorial Trotta, 2010.

FERREIRA, Carlos Enrique Ruiz. O imigrante como um subversivo prático-político, possibilidade de um "novo mundo" - o projeto universal-cosmopolita dos Direitos Humanos em contraposição à Soberania territorial. Emancipação. Ponta Grossa, v. 11, n. 2, p. 253-266, 2011

FOUCAULT, Michel. História da Sexualidade I: A Vontade de Saber. Trad. Maria Thereza da Costa Albuquerque e J. A. Guilhon Albuquerque. 22a . Impressão. Rio de Janeiro: Edições Graal, 2012.

HARDT, Michael; NEGRI, Antonio. Multidão: guerra e democracia na era do Império. Trad. Clóvis Marques. São Paulo: Record, 2005.

JAKOBS, Günther. La autocomprensión de la ciencia del Derecho penal ante los desafíos del presente. Trad. Teresa Manso. In: MUÑOZ CONDE, Francisco (coord.). La ciencia del Derecho Penal ante el nuevo milenio. Valencia: Tirant lo Blanch, 2004. p. 53-64.

MANETTA, Alex. Bolivianos no Brasil e o discurso da mídia jornalística. In: Baeninger, Rosana (Org.). Imigração boliviana no Brasil. Campinas: Núcleo de Estudos de PopulaçãoNepo/Unicamp; Fapesp; CNPq; Unfpa, 2012. p. 257-270.

NASCIMENTO, Daniel Arruda. Do fim da experiência ao fim do jurídico: percurso de Giorgio Agamben. São Paulo: LiberArs, 2012.

PÉREZ, María Luisa Bacarlett. Giorgio Agamben. Del biopoder a la comunidad que viene. Araucaria: Revista Iberoamericana de Filosofía, Política y Humanidades. Ano 12, n. 24, p. 28-52, 2010.

SANTOS, André Leonardo Copetti. A repressão das diásporas em tempos globais e os direitos humanos dos migrantes. In: BEDIN, Gilmar Antonio (org.). cidadania, direitos humanos e equidade. Ijuí: Editora UNIJUÍ, 2012. p. 337-374.

SAYAD, Abdelmalek. A imigração ou os paradoxos da alteridade. Trad. Cristina Murachco. São Paulo: Edusp, 1998.

SOUSA SANTOS, Boaventura de. Nuestra América: reiventar um paradigma subalterno de reconhecimento e redistribuição. In: SOUSA SANTOS, Boaventura de. A gramática do tempo: para uma nova cultura política. 2. ed. São Paulo: Cortez, 2008. 


\section{Sobre os autores:}

Maiquel Ângelo Dezordi Wermuth é Doutor em Direito Público pela Universidade do Vale do Rio dos Sinos (UNISINOS). Professor do Mestrado em Direitos Humanos da Universidade Regional do Noroeste do Estado do Rio Grande do Sul (UNIJUÍ) e dos Cursos de Graduação em Direito da UNIJUÍ e UNISINOS. Endereço Eletrônico: madwermuth@ gmail.com

Terezinha de Camargo Viana é Doutoranda em Direito pela Universidade do Vale do Rio dos Sinos (UNISINOS). Mestre em Direito pela UNIJUÍ. Professora do Curso de Graduação em Direito da UNIJUI. Endereço Eletrônico: joice.gn @ gmail.com 